\title{
GREEN ROOF: A HOLISTIC APPROACH FOR ECOLOGICALLY SUSTAINABLE CITIES
}

\author{
Dr. Imad M. Assali \\ Interior Design Department, College of Arts \& Science, \\ Ahlia University, Kingdom of Bahrain
}

\begin{abstract}
Sustainable technologies and green design practices all over the world have a vital role on architectural practices by reducing building impacts on human health and the environment and contribute positively to the ecosystem. Factors call for improved environmental design are population growth, which increases the built up area in cities and reduce the green open spaces, high percentage of air and water pollution due to industrialization, global warming, loss of habitat and biodiversity, and increasing urban heat island (UHI). Consequently, a new approach is needed to alleviate these problems; one of these approaches is green roofs which recognized as an effective sustainable design tool that soften the harsh urban environment. Green roofs or the so called 'fifth facade' have had diverse environmental benefits such as improving the surrounding environment, insulation properties, purifying the air pollutants through the foliage which absorb dust particles, carbon dioxide, and other pollutants, building energy saving, it also presents the correlation between a green rooftop and improving micro-climate for both individual buildings and neighborhood. In addition, green rooftops provide a visual interesting layer with plenty texture and color instead of uncovered roof. Generally, the results verified that green-roof enhance building microclimate, conserve energy, increase occupants' comfort and health, and compensates for the green-space deficit in cities.
\end{abstract}

Keywords: green roof, environment, green design, sustainable development

Cite this Article: Dr. Imad M. Assali, Green Roof: A Holistic Approach for Ecologically Sustainable Cities, International Journal of Civil Engineering and Technology, 11(6), 2020, pp. 31-39.

https://iaeme.com/Home/issue/IJCIET?Volume $=11 \&$ Issue $=6$

\section{INTRODUCTION}

Green rooftop is a sustainable technique that improves both the interior environment of buildings and the built environment. The relationship of man and nature back dated to primitive era that connects humans with nature. Therefore, the advantages of green spaces are more than just aesthetics, as these green spaces can reduce urban heat island (UHI) resulting from the abundance of streets in cities [1,2]. In addition, plants clean the air as they remove pollutants from the air and lower temperatures [3]. 
Nowadays, cities suffer from the disappearance of green open spaces as a result of urbanization which increase hard surface represented by streets and the neglected and underutilized building's roof. In this manner, these rooftops have the opportunity to solve the deficit of green spaces figure 1 .
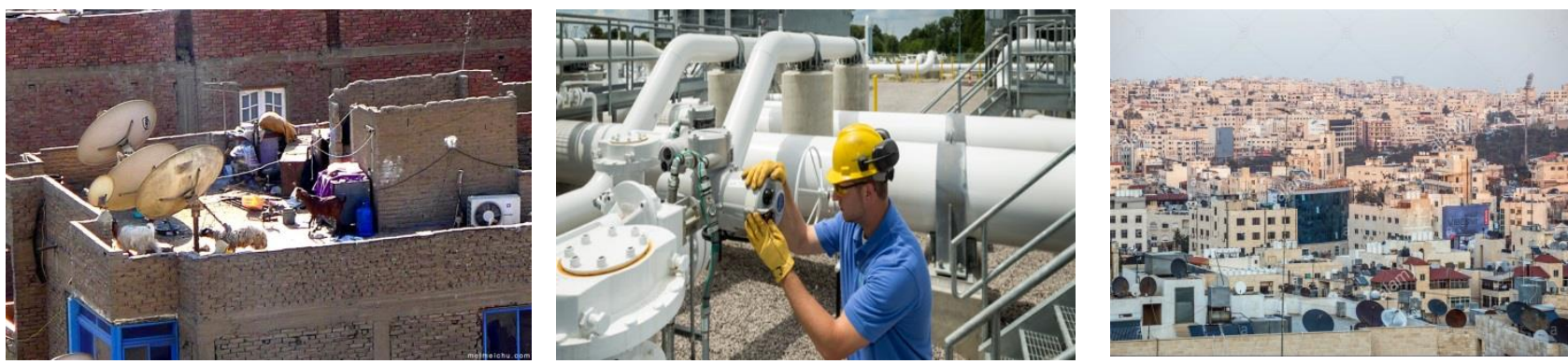

Figure 1 The condition of building rooftop.

This research will be reviewing related scientific articles in journals through the database; it will also provide an overview of research findings concerning the environmental advantages of extensive green rooftop towards a sustainable environment. Finally, this research recommends decision makers and designers to adopt the green rooftop concept in the new architecture.

\subsection{Historical Background of Green Rooftop}

Since earliest recorded times, the idea of designing elevated green spaces is not a new one. The most known example of roof gardens is the ancient ziggurat of Mesopotamia built between 4,000 - $600 \mathrm{BC}$, as trees and flowers were distributed on different level terrace reached by an outside stairs figure 2 .

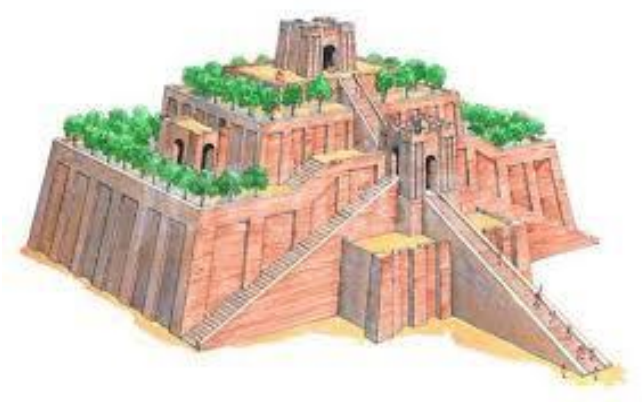

Figure 2 The ziggurat with green rooftop

Nebuchadnezzar the king of Babylon built the Hanging Gardens of Babylon 2700 years ago is an example of green rooftop. Romans also involve in roof terracing as shown in the Augustus Mausoleum in Rome. The construction of roof terraces still considered to be a manner of prestige and dominance during the Roman period and well into the Renaissance period, and later to the rest of classical culture. Nowadays, modern architects endorsed the advantages of green rooftops and become part of their designs. One of the examples of modern green rooftops in 1930s is the Rockefeller Roof Gardens in New York inspired the design concept from the hanging gardens of Babylon [4] figure 3. 

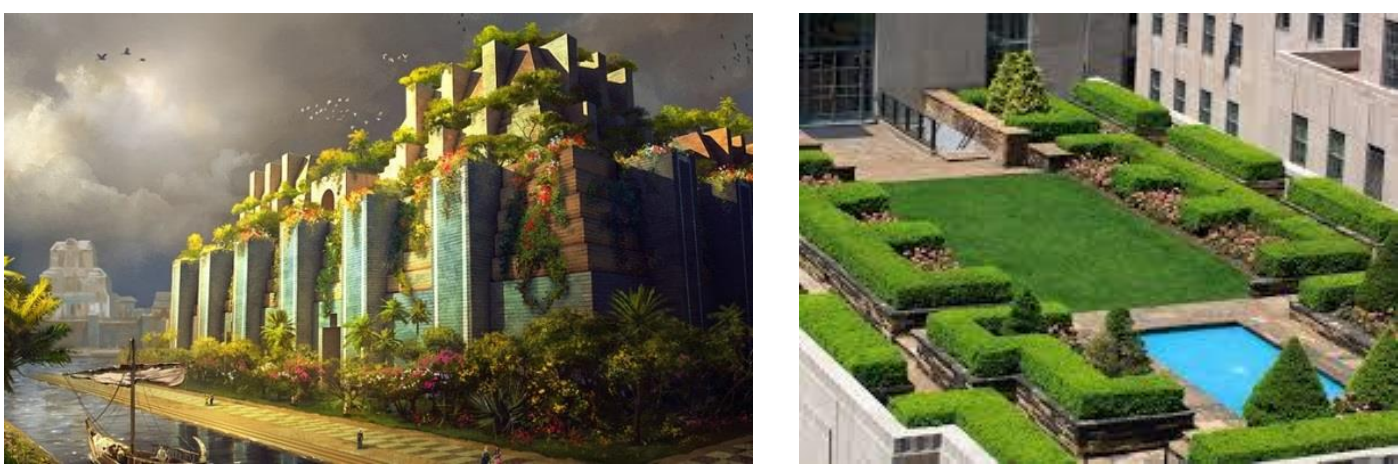

Figure 3 a-The Hanging Gardens of Babylon

b- Rockefeller Roof Garden in New York

The development of green rooftops from traditional architecture started in Germany in 1970 as different researchers worked on the advent of root barriers to make the concept of green rooftop viable [4].

\subsection{Green-Roof Elements}

A green rooftop is made out of the following layers figure 4:

- Plant layer- plants usually absorb the Sun heat keep the roof cool, provides biodiversity to the roof, also provide additional oxygen to the building. In addition, choosing native plants reduce maintenance and the need for irrigation.

- Growing Medium or soil substrate -should have the capability to absorb water, retain it and retain and have an efficient drainage system.

- Root barriers - protect the membrane from being penetrated from roots growing. These root barriers should be durable to reduce the cost of material replacement and reduce the leak.

- Drainage Layer -to ensure runoff drainage and protect water proof membrane.

- Insulation- refers to sealants used to weatherproof concrete substrate.

- Filter fabric - this layer is an extension of the green rooftop drainage layer that removes particles from the drain.

- Waterproof membrane - this main function of this layer is keeping moisture out of the structure.

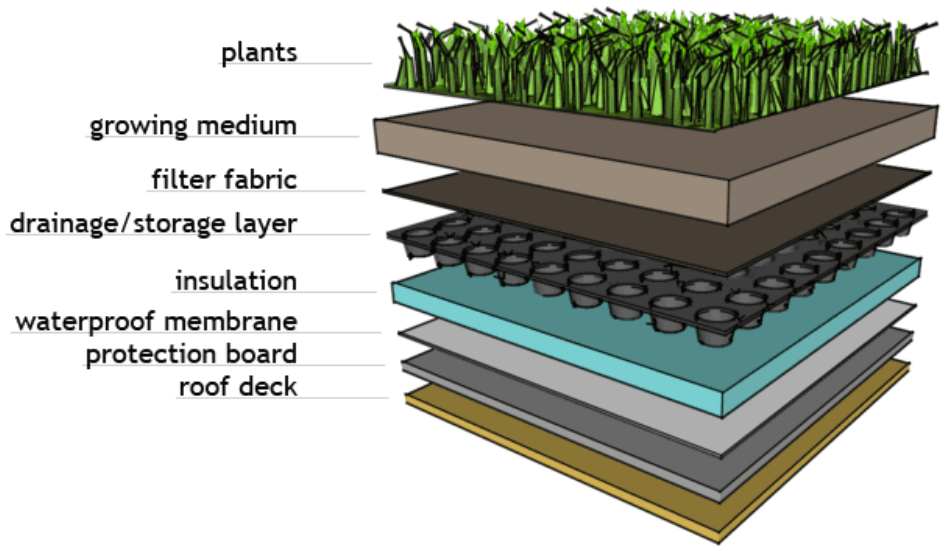

Figure 4 Green rooftop layers [5] 


\subsection{Research Problem}

Most cities face a challenge of rapid urbanization causing disappearance of green spaces in addition to different environmental problems that destroy ecosystems, such as the fastgrowing population, pollution, urban heat island, dense urbanization, and economic problems as a result of using HVAC systems.

\subsection{Research Purpose}

The purpose of this research is to address environmental benefits and challenges of green rooftops and recommends ways to reduce these challenges. Therefore, this research answers the following questions:

- What are the advantages of installing green rooftops?

- What are the challenges of green rooftop installation, and how to maximize their benefits?

\subsection{Methodology}

The study conducted a review of journals and articles using the most updated data emphasized on the advantages of green rooftops. Then, this research examines successful case studies and introduces the challenges and the successful practices for implementation.

\section{LITRETURE REVIEW}

A review of the literature indicates that different terms representing green rooftop such as Eco roof, Bio roof, Living roof, which can be defined as growing plants on rooftops of buildings and replace the gardens at ground level. Generally, green rooftop started in Germany and the invention of green roof flourished in other counties in Europe and Asia [6,7 ], figure 4 shows some examples of green rooftops around the world. In addition, many green roofs appear with different colors because their leaves change their color as a result of season change and a diversity of plants used.
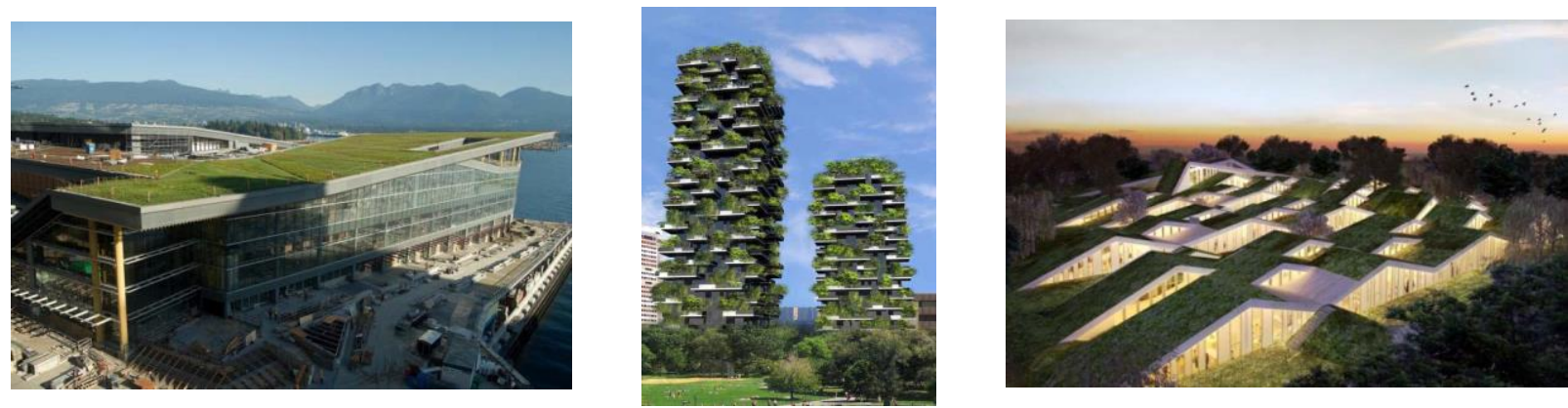

a- Bjarke Ingels - school in Asminderod b- Vancouver convention Centre c- Bosco Verticale in Milan

Figure 4 Different Examples of green rooftops around the world

\subsection{Types of Green Roofs}

Green rooftops are mainly two types, extensive and intensive [8]. These two types differ from each other in the: substrate layer thickness, plants type, and irrigation system, see figure $5 \&$ Table 1. The extension type is a lightweight green roof has a thickness between 4 and $15 \mathrm{~cm}$. On the other hand, intensive roof is a normal garden which depth ranges from $15 \mathrm{~cm}$ to as much as $150 \mathrm{~cm}$ which make it suitable for shrubs and trees which required an expensive support structure to bear its weight. Hence, the main vegetation used in green roofs should be native plants, the common reasons for choosing native plants are these plants adapted to the 
local conditions as they do not need watering, fertilizers or pesticides [6]. Nonetheless, extensive green roof is the most common type as it is least expensive in terms of installation, maintenance, and can survive in arid climates [6].
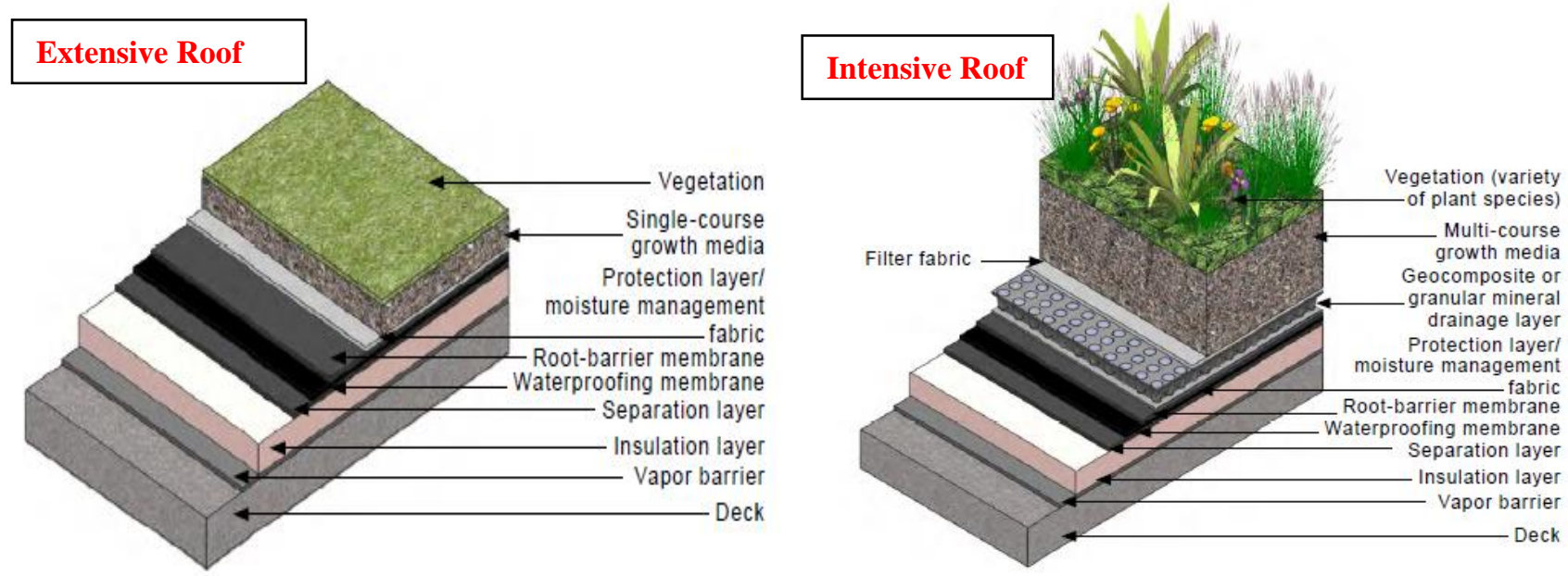

Figure 5 Green Roof Types [9; pp.: 6].

Table 1 Extensive vs. Intensive Green roofs [4,7].

\begin{tabular}{|c|l|l|}
\hline & \multicolumn{1}{|c|}{ Extensive } & \multicolumn{1}{c|}{ Intensive } \\
\hline 1 & Lightweight & Heavier weight/greater diversity of plants \\
\hline 2 & Low growing plants & Trees, shrubs and more \\
\hline 3 & $\begin{array}{l}\text { Low growing plants, climate } \\
\text { tolerance }\end{array}$ & $\begin{array}{l}\text { No restrictions on plant selection depend } \\
\text { on climate }\end{array}$ \\
\hline 4 & $\begin{array}{l}\text { Suitable for flat and sloped } \\
\text { roofs }\end{array}$ & Suitable for flat roofs \\
\hline 5 & $\begin{array}{l}\text { Structural requirements: } \\
\text { Within structural roof load. }\end{array}$ & Should be considered in design phase \\
\hline 6 & No irrigation required & Irrigation usually necessary \\
\hline 7 & Low maintenance costs & Higher maintenance costs \\
\hline
\end{tabular}

The most common vegetation used is Sedum because of the following and unique characteristics:

- Sedum has very shallow roots which need a modest depth of the substrate layer;

- It is short in height as it has a low growing rate;

- Sedum is also drought-resistant as it has water-storing leaves;

- Sedum also has a crassulacean acid metabolism i.e.: CAM photosynthesis;

- Finally, seldom needs relatively little nutrients compared to other types of plant.

\subsection{Advantages of Green Roofs}

Generally, global warming, air and water pollution, and urban heat island effects (UHI) urge for sustainable environmental design. Therefore, implementing green roofs will raise the ratio of green areas in the built environment, which disappeared as a result of massive construction activities and through urban-renewal schemes. In the meantime, green roofs can be applied to all building types such as residential buildings, offices, schools, and not limited to a specific building type $[10,7]$.

Furthermore, the most exposed surfaces to the sun among the external envelopes are building's roof, which make them receive the most solar radiation through the day [11]. 
Different studies show that green roof protects both the roof structure and the interior building environment from extreme temperatures, save the cost of roof insulation, increase the durability of roofing membranes, and reduce energy consumption of buildings $80 \%[12,13]$. Other studies showed that the interior temperature of buildings with green roofs is lower than those buildings without a green roof by $100 \mathrm{C}$ which as a result reduce air-condition or heating costs [14].

In addition, green roofs encourage the biodiversity of birds, insects and plants and also offer an aesthetic beauty. Moreover, planting rooftops is one of the ways in reducing pollutants as plant foliage absorbs these pollutants by their leaves. Furthermore, green roof mitigate the urban heat island effect (UHI), the most efficient method is by increasing green areas in cities which decrease thermal gain [15]. Also, green roofs reduce storm water runoff and improve rainwater retention and help to reduce flash flood [7]. Simultaneously, therapeutic green roof creates beauty, speeds recovery rates and reduce drug use in hospitals and other health care facilities [4]. Health care research indicates that Patients with trees view recover faster and had a few lengths of hospitalization compared to those who have no window view $[16,17]$.

On the contrary, the disadvantages of green roofs are the cost. Usually, costs vary depending on the growing medium, type of roofing membrane, quantity of plants and drainage system [6]. Nevertheless, cost is not a disadvantage as green roofs reduce thermal gain from plant shading, increase thermal insulation, and acoustical insulation, which cool air and surface temperatures, all of which decreases depending on HVAC system for building interiors $[18,19]$.

Furthermore, the economic benefits of green roofs are numerous, including creating new employment opportunities for city dwellers in design, construction, and installation. In addition, green roofs increase the property values in branding it as a green building [17]. Also, green roofs can produce healthy foods and plants, which reducing associated transportation and refrigeration costs [20].

Also, the increasing price of energy calls for the adoptions of other sustainable and renewable energy sources for electricity generation, such as photovoltaic (PV) technology that generate clean energy from the sun need a temperature around $80^{\circ} \mathrm{F}$ which can be provided by green roofs [15]. As the average temperature of an asphalt or underutilize roof is between $160^{\circ} \mathrm{F}$ and $180^{\circ} \mathrm{F}$ which decrease their efficiency of PV [4].

\subsection{Challenges of Installing Green Roof}

Recently, the installation of green roofing is widely spread in different European countries for their environmental benefits, but still unknown in other regions. There are several challenges that must be addressed for a successful green roof project. Here are a few (but certainly not all).

- The lack of experienced professionals who have the experience to deal with leaks, plants type in relation to area climate, and drainage system.

- Choosing the right plants without the proper consideration to adapt to a specific climate is critical end up killing all the plants.

- Maintenance is very important in taking care of green roof as mentioned before green roof has different layers so it need someone who have the knowledge to maintain them without killing the vegetation. Furthermore, the roof is structure is the main base for green roofs, therefore it should be strong enough to hold all the plants and grow medium (typically soil). 
- Lack of awareness among different stakeholders such as buildings' owner, designers, and researchers.

- Cost creates interrelated challenge to green roof implementation.

\subsection{Green Roof Design Consideration}

This part displays the best methods that help buildings' owners, occupants, designers to get the better practice about green roof techniques and to overcome all the challenges which encourage their adoption.

- Use: The main function of green roof in a building (i.e.: Green roof designed to retain storm water from one designed for roof beautification) affect the overall design, budget, and the selection of professional consultants. Specialist consultants may include a structural engineer, a landscape architect, and horticulturist.

- Location \& Plants: The location of green roof is very important as it is influenced by wind direction, the sun which affects plant selection. In addition, climatic conditions can be controlled by different methods such as pergolas, trellis that give shade to the area [6].

- Structure: The cost of installing a green roof on an existing building is higher than a new building, as existing building limit the carrying capacity of the existing roof.

- Roofing: check the waterproofing for an existing green roof system and the drainage system [20].

- Maintenance: Green roof required regular maintenance inspections for plants and waterproofing membrane to check irrigation, pruning, and replanting.

\section{EXAMPLES FROM LITRETURE}

\subsection{School of Arts, Design and Media- Singapore}

This project designed by CPG Consultants completed in 2006 received an award from the Singapore Building and Construction Authority. The design concept of the campus challenges the traditional education buildings using an organic shape with green rooftop with different advantages like insulating the building from thermal heat gain, storm water management, and serve as gathering places for students, faculty, and visitors.
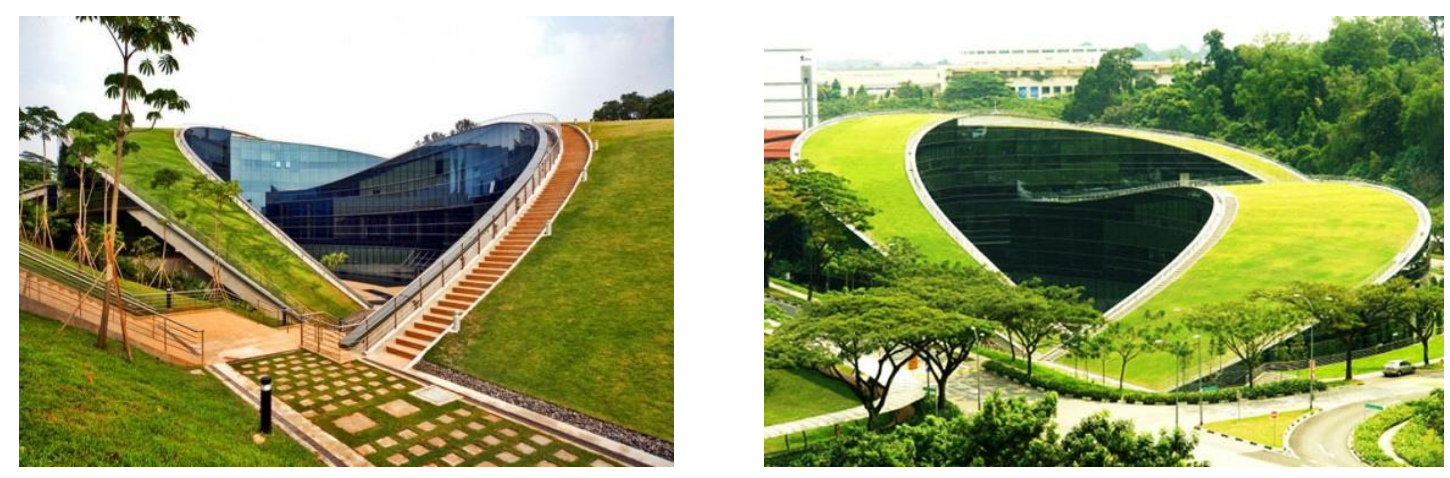

Figure 6 School of Arts, Design \& Media [9; pp.: 6].

\subsection{Japan's Namba Commercial Center}

The shopping mall in Osaka, Japan by the Jerde Partnership. The shopping mall complex crowned with a rooftop park amidst Osaka's dense urban streets reinforces the connection with nature and encourages the interaction of people. The architecture of the building emerges and is improved with the successful coexistence between structural and planting materials. 
The bioclimatic advantages add a long term, low cost function to the building and increase the environmental benefits.
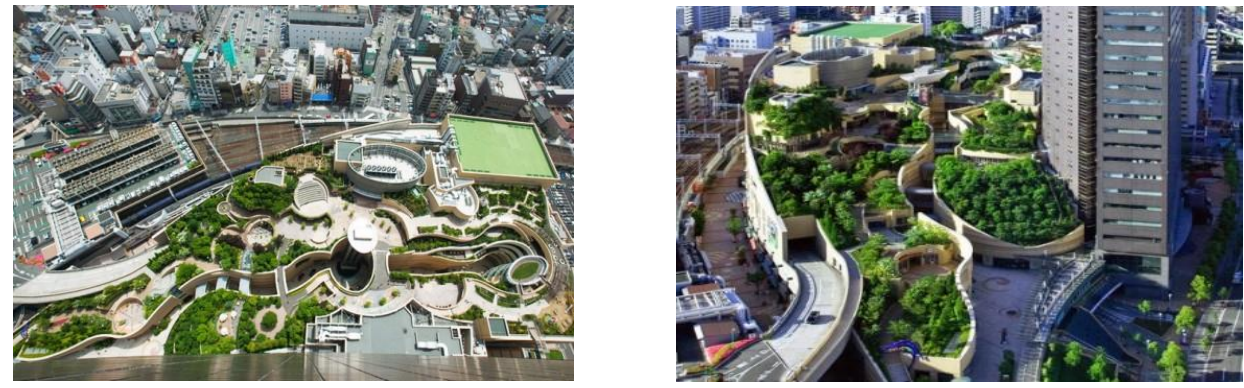

Figure 7 Namba Commercial Center [21]

\section{CONCLUSION}

Green roofs have different benefits to the environment vary from aesthetic values, economic and climatic values. This research shows how to increase green areas in neglected areas like building rooftop. Different challenges to green roof installation may be cost, lack of technical knowledge and awareness among stakeholders, and lack of governmental support. In addition, it is important that governments should lead the planning and designing process for the implementation of green roof systems. I believe that the success of green roof can be accomplished by all the people involved in the design like architects, structural engineers, landscape architect, and horticulturists. Finally, this study presents the importance of green roofs development. Therefore, academic institutes must start introducing in their curriculum subjects related to sustainable landscape design. In addition, they must hire qualified professional faculty members to spread the concept of sustainable landscape design.

\section{REFERENCES}

[1] Elpiniki C., Julia G., Declan R. (2009). Roof gardens: an opportunity to expand the art of landscape architecture. Energy, Environment, Ecosystems, Development and Landscape Architecture.

[2] Mithraratne N., Low F. (2014). Hanging gardens in cities: Are they really beneficial as an add-on? Fifth International Conference on The Constructed Environment', University of Pennsylvania, Philadelphia, 16-17 October 2014.

[3] Attia S., Hegazy A.A. (2009). Green Roofs in Cairo: A Holistic Approach for Healthy Productive Cities. 7th Annual Greening Rooftops for Sustainable Communities conference, At Atlanta, USA

[4] Velazquez L.S. (2005). Organic Greenroof Architecture: Sustainable Design for the New Millennium: Making the most of your building's "fifth façade". Wiley Periodicals, Inc.

[5] https://myrooff.com/green-roof-layers/

[6] Li W.C., Yeung K.K.A. (2014). A comprehensive study of green roof performance from environmental perspective. International Journal of Sustainable Built Environment (2014) $3,127-134$.

[7] Abdul Rahman S. R., Ahmad H., Rosley M.S.F. (2013). Green Roof: Its awareness among professionals and potential in Malaysian market. ASEAN Conference on EnvironmentBehaviour Studies Hanoi Architectural University, Hanoi, Vietnam, 19-22 March 2013.

[8] www.sempergreen.com/en/solutions/green-roofs/frequently-asked-questionsgreenroof/what-is-an-extensive-green-roof 
[9] https://www.gsa.gov/portal/mediaId/158783/fileName/The_Benefits_and_Challenges_of_ Green_Roofs_on_Pub lic_and_Commercial_Buildings.action

[10] Iyengar K. (2015). Sustainable Architectural Design: An Overview. Routledge. NY.

[11] Cartleton H.f., Stovin V., Beck S.B.M., Davison J.B. (2010). Green Roof: building energy savings and the potential for retrofit. Energy and Buildings 42 1582-1591.

[12] Jaffal I., Ouldboukhitine S.E., Belabi R. (2012). A comprehensive study of the impact of green roofs on building energy performance Renew. Energy, 43 (2012), pp. 157-164.

[13] Peng L.L.H, Jim C.Y. (2013). Green-Roof Effects on Neighbourhood Microclimate and Human Thermal Sensation. www.mdpi.com/journal/energies

[14] Ismail A., Abdul Samad M.H., and Abdul Rahman A.M. (2011). The Investigation of Green Roof and White Roof Cooling Potential on Single Storey Residential Building in the Malaysian Climate. World Academy of Science, Engineering and Technology International Journal of Civil, Environmental, Structural, Construction and Architectural Engineering Vol: 5, No:4, 2011.

[15] Sheng L.X., Ariffin A. R. B. M., Hussein H. B., (2011). Assessing the Green Roof Technology in Green Building Rating Systems. International Building \& Infrastructure Technology Conference. 7-8 June 2011, Penang, Malaysia.

[16] Ulrich R.S. (1984). View through a window may influence recovery from surgery. Science. 224, pp. 420-421.

[17] Shimmin H. (2012). London the Vertical Garden City and The Transformative Power of Roof Gardens. Ma in Historical and Sustainable Architecture Thesis New York University.

[18] Gedge D. Newton J. Cradick C. Cooper P. (2008). "Living Roofs and Walls, Technical Report: Supporting London Plan Policy" Greater London Authority: London, 2008. http://static.london.gov.uk/mayor/strategies/sds/docs/living-roofs.pdf

[19] Liu k. Baskaran B. (2003). Thermal Performance of Green Roofs through Field Evaluation. National Research Council of Canada May 2003, 4.

[20] https://www.eugene-or.gov/DocumentView.aspx?DID=1049

[21] http://inhabitat.com/japans-namba-parks-has-an-8-level-roof-garden-with-waterfalls/ 